\title{
The TerraSAR-X Orthorectification Service and its Benefit for Land Use Applications
}

\author{
Martin Huber, Birgit Wessel, Achim Roth \\ German Remote Sensing Data Center \\ German Aerospace Center (DLR) \\ Oberpfaffenhofen, Germany \\ (martin.huber, birgit.wessel, achim.roth)@dlr.de
}

\begin{abstract}
The German Aerospace Center (DLR) currently develops the TerraSAR-X Payload Ground Segment. On request level $1 \mathrm{~b}$ products will be distributed to the user. Two of the four basic products available are generated by the geocoding system. This system supports ellipsoid and terrain correction in order to provide orthorectified images. A new product called Enhanced Ellipsoid Corrected (EEC) will be offered that considers Digital Elevation Models (DEMs) of a moderately coarser resolution than the resolution of the TerraSAR- $X$ modes. SRTM/X-band DEMs with approximately $25 \mathrm{~m}$ resolution will be the backbone for this operational and fully automated service. For high precision terrain correction first results of an experimental processor are presented using a high resolution DEM, tiepointing and image adjustment.
\end{abstract}

Many land use applications are in need of orthorectified images to conduct their analyses. This paper shows some examples and gives information about the anticipated image geometry of these products.

Keywords-TerraSAR-X; Geocoding; Orthorectification

\section{INTRODUCTION}

TerraSAR-X is a new German radar satellite, which shall be launched in October 2006. Its high frequency X-band SAR sensor can be operated in different modes and polarizations. High resolution SAR images will be recorded in single, dual and quad-polarization. Different incidence angles are supported by beam steering and double side access can be realized by satellite roll manoeuvres. TerraSAR-X will be positioned in an 11 days repeat pass orbit with a scheduled lifetime of five years.

Currently, the TerraSAR-X Payload Ground Segment for receiving, processing, distribution and archiving of the X-band SAR data is developed at the German Aerospace Center (DLR). Besides two geocoded basic products also a single look complex (in slant range) and a multi-look detected product (in ground range) will be available. The geocoded products are provided for multi-resolution and multi-polarization data. They are named: "Geocoded Ellipsoid Corrected" (GEC) and "Enhanced Ellipsoid Corrected" (EEC). Backbone for this global orthorectification service are the DEMs provided by the SRTM mission. They cover almost $80 \%$ of the land surface. DEMs from other sources (e.g. ERS, GLOBE) complement the elevation information and are stored in a DEM-database (DEM-DB).

The experimental "Geocoded Terrain Corrected" (GTC) product utilizes high resolution DEMs (e.g. from laserscanning). As the DEM resolution gets close to the SAR image resolution the geometric fitting between DEM and the SAR image is crucial. Therefore, ground-control points and image adjustment techniques are used for a highly accurate pixel allocation.

Additionally, a Geocoded layover shadow and Incidence angle Mask (GIM) can be generated as a by-product to EEC and GTC. It provides information about the local incidence angle for each pixel of the geocoded SAR scene and about presence of layover and shadow areas. This information can be valuable for further analyses.

The accuracy of the orthorectification mainly depends on the quality of the used DEM. The impact of the different DEM qualities on the pixel location accuracy will be outlined. In this paper high resolution airborne SAR data are used for testing and quality analysis.

\section{SAR GEOCODING}

Due to the side looking geometry of SAR systems undulated terrain is significantly distorted in SAR images. The most important local image distortions that occur are foreshortening, layover, and shadow [1]. These effects can be corrected using a digital elevation model.

Three different approaches for geocoding TerraSAR-X images are used [2]: the rigorous Range-Doppler Approach (for GTC), the 3D Interpolative Approach (for EEC) and the Interpolative Approach (for GEC).

The rigorous Range Doppler Approach is used for the GTC generation. For each output pixel, which defines a co-ordinate triple (easting, northing, height) in the output map projection, the corresponding azimuth and range positions in the input image have to be determined. This is based on the RangeDoppler and Range equations applicable to SAR images. Due to the dynamic imaging principle of SAR this is an iterative and hence time consuming search procedure. In order to improve the throughput of the SAR processor the EEC generation applies the $3 D$ Interpolative Approach. The rigorous transformation is performed for grid points only and 
interpolation is used to fill these grid cells. The GEC generation applies the Interpolative Approach, which is a special case of the $3 \mathrm{D}$ interpolation, as only a constant height is applied. Common to all approaches is the backward geocoding method also denoted as object-to-image approach.

Rigorous and interpolative ellipsoid corrections are parametric geocoding approaches. Multi-polarized data are handled as multi-layer images, where the geometric calculation is performed only once for all layers.

The pixel location accuracy depends on the orbit precision, SAR processing, SAR geocoding and the DEM accuracy. Depending on the time span between acquisition and processing quicklook $( \pm 10 \mathrm{~m})$, rapid $( \pm 2 \mathrm{~m})$ or science orbits $( \pm 20 \mathrm{~cm})$ will be used for orthorectification. These orbit errors cause pixel location offsets in the same order. Regarding solely the SAR processing and geocoding procedures accuracies as shown in TABLE I are achieved. The impact of potential DEM errors on the pixel location accuracy is shown in the following chapter.

\section{Digital Elevation Model Data Base}

The task of the Digital Elevation Model Data Base (DEM$\mathrm{DB})$ is the storage and provision of elevation information for the orthorectification process and geometric calculations. The DEM-DB supports multiple resolutions and keeps the elevation data in tiles. The database organization as well as the elevation data representation is in geographic co-ordinates. Different elevation models like the SRTM C-band and the SRTM Xband derived elevation products can be organized in separate projects. The finest resolution supported is $0,01 "(\approx 0,3 \mathrm{~m})$.

The DEM-database itself consists of a file configuration and management system and a package of software modules for file access and data manipulation. The processing capability comprises transformation into a different map projection or geodetic datum, merging and mosaicking of different resolutions and qualities [3] as well as DEM colour shading and visualisation [4].

The availability and quality of a DEM is decisive for the generation of orthorectified images. The DEM-sources used for the operational TerraSAR-X orthorectification service are listed in TABLE II.

TABLE III shows the relation between an elevation error and the resulting location error in the orthorectified image. One can see that the resulting location error decreases with increasing incidence angle.

TABLE I. EFFECT OF SAR PROCESSING AND GEOCODING PROCEDURE ON THE PIXEL LOCATION ACCURACY

\begin{tabular}{|c|c|c|c|c|}
\hline & \multicolumn{4}{|c|}{ Pixel Location Accuracy [m] } \\
\hline $\begin{array}{c}\text { Incidence } \\
\text { angle }\left[^{\circ}{ }^{\text {J }}\right.\end{array}$ & $\begin{array}{c}\text { High } \\
\text { Resolution Spot } \\
\text { Light }\end{array}$ & $\begin{array}{c}\text { Spot } \\
\text { Light }\end{array}$ & $\begin{array}{c}\text { Strip } \\
\text { Map }\end{array}$ & ScanSAR \\
\hline 20 & 2.0 & 2.0 & 2.0 & 8.0 \\
\hline 45 & 0.8 & 1.0 & 1.5 & 8.0 \\
\hline
\end{tabular}

TABLE II. CHARACTERISTICS OF AVAILABLE DEM SOURCES

\begin{tabular}{|c|c|c|c|c|}
\hline \multirow{2}{*}{$\begin{array}{c}\text { DEM } \\
\text { product }\end{array}$} & \multicolumn{2}{|c|}{$\begin{array}{c}\text { vertical } \\
\text { accuracy }\end{array}$} & \multirow{2}{*}{$\begin{array}{c}\text { grid } \\
\text { size [“] }\end{array}$} & \multirow[b]{2}{*}{ limitations } \\
\hline & $\begin{array}{c}\text { Relat } \\
\text { ive } \\
\text { [m] }\end{array}$ & $\begin{array}{c}\text { Absol } \\
\text { ute } \\
\text { [m] }\end{array}$ & & \\
\hline $\begin{array}{l}\text { SRTM / X- } \\
\text { SAR }\end{array}$ & 6 & 16 & 1 & $+-60^{\circ}$ with gaps \\
\hline $\begin{array}{l}\text { SRTM / C- } \\
\text { SAR }\end{array}$ & 8 & 16 & 3 & $+-60^{\circ}$ \\
\hline ERS-tandem & 20 & 30 & 1 & limited availability \\
\hline DTED-1 & 20 & 30 & 3 & limited availability \\
\hline GLOBE & \multicolumn{2}{|c|}{$\begin{array}{l}\text { varying: } 10 \mathrm{~m}- \\
100 \mathrm{~s} \text { of meters }\end{array}$} & 30 & $\begin{array}{c}\text { no restrictions, poor } \\
\text { quality }\end{array}$ \\
\hline
\end{tabular}

TABLE III. IMPACT OF ELEVATION ERROR ON LOCATION ACCURACY

\begin{tabular}{|c|c|c|c|c|c|}
\hline & \multicolumn{5}{|c|}{ Pixel Location Accuracy [m] } \\
\hline $\begin{array}{c}\text { Incidence angle } \\
\text { [ }{ }^{\text {] }}\end{array}$ & $\mathbf{2 0}$ & $\mathbf{2 6}$ & $\mathbf{3 5}$ & $\mathbf{4 4}$ & $\mathbf{5 0}$ \\
\hline $\begin{array}{c}\text { Displacement } \\
\text { factor }\end{array}$ & $\mathbf{2 , 7 5}$ & $\mathbf{2 , 0 5}$ & $\mathbf{1 , 4 3}$ & $\mathbf{1 , 0 3}$ & $\mathbf{0 , 8 3}$ \\
\hline $\begin{array}{c}\text { DEM elevation } \\
\text { error [m] }\end{array}$ & & & & & \\
\hline $\mathbf{2}$ & 5,5 & 4,1 & 2,9 & 2,1 & 1,7 \\
\hline $\mathbf{8}$ & 42 & 16 & 12 & 9 & 7 \\
\hline $\mathbf{1 6}$ & 82 & 61 & 43 & 31 & 25 \\
\hline $\mathbf{3 0}$ & & 33 & 23 & 17 & 13 \\
\hline
\end{tabular}

If a DEM is provided for EEC generation an additional auxiliary file is created, the so called "DEM Coverage Map". It contains information about the DEM sources used for the orthorectification. It covers the same area like the DEM but in a reduced resolution. It is co-registered to the EEC image.

\section{STANDARD ORTHORECTIFIED IMAGES}

Two geocoded basic products will be available from TerraSAR-X, the Geocoded Ellipsoid Corrected (GEC) and the Enhanced Ellipsoid Corrected (EEC). The standard projection for both is Universal Transverse Mercator (UTM). For Polar regions Universal Polar Stereographic (UPS) will be applied. WGS84 is used as geodetic datum. The image data which consist of one or more polarimetric layers are stored in individual GeoTIFF files. The product annotation is stored in the Extensible Markup Language (XML) format. For more details about the product format refer to [5].

\section{A. Geocoded Ellipsoid Corrected}

The Geocoded Ellipsoid Corrected (GEC) product is a multi-look detected product. As the ellipsoid correction does not consider a DEM (only an average height), the pixel location accuracy varies due to the terrain. The terrain induced distortions will not be corrected and significant differences can appear in particular for strong relief and steep incidence angles. The GEC is generated by applying the interpolative ellipsoid correction approach [2]. 
The GEC is the recommended product for marine and coastal applications where topography doesn't affect the location accuracy.

\section{B. Enhanced Ellipsoid Corrected}

Like the GEC, the Enhanced Ellipsoid Corrected (EEC) is a multi-look detected product. Terrain induced distortions are corrected considering a DEM of a moderately coarser resolution then the TerraSAR-X products. The pixel location accuracy in these products is considerably more accurate than in GEC images. The geometric quality depends on the height accuracy and resolution of the DEM in combination with the type of terrain and the incidence angle.

It is expected that the EEC will become the standard geocoded product of TerraSAR-X. Like the GEC the EEC is generated automatically. No operator interactions are required.

\section{Geocoding Results and Application Example}

High resolution airborne SAR data provided by DLR's experimental airborne system E-SAR were used for testing and quality analysis. Several images with a size of $3 \times 10 \mathrm{~km}$ were acquired covering the cities of Ludwigshafen and Mannheim in south-west Germany.

\section{1) Geocoding Results:}

In this relatively moderate terrain a GEC as well as an EEC was generated with an output resolution of two meters. For the GEC product an average height of $143 \mathrm{~m}$ was assumed. For the EEC the elevation information was extracted from the SRTM X-band 1" DEM dataset and ranged between $108 \mathrm{~m}$ and $175 \mathrm{~m}$. Depending of the incidence angle and the height difference the pixel location deviation between GEC and EEC varies up to tens of meters (cf. TABLE III). Especially topographic features like the Upper Rhine valley or small scale features like hills are geo-referenced far better in the EEC product.

\section{2) Application Example :}

At the German Remote Sensing Data Center a study was carried out to investigate the potential use of high resolution SAR data in the context of urban applications [6]. The goal was to support regional and urban planning. The provided EEC images were helpful for the developed approach towards an automated analysis of the land use pattern in urbanized areas. Especially for the classification accuracy assessment the orthorectified images were of great value for comparisons with reference data (Fig. 1).

\section{High PRECISION ORTHORECTIFIED IMAGES}

Besides the operational geocoding system an experimental processor is under development which focuses on high precision geocoding. The resulting product is the Geocoding Terrain Corrected (GTC). It needs a DEM of approximately the same resolution like the SAR image with high position accuracy. Within the processor the rigorous Range-Doppler approach is used for mapping [2]. The approach is based on tiepoints and image adjustment to fit the radar image to a reference, e.g. to a high precision image or to a DEM. GTC processing is especially recommended for urban areas.

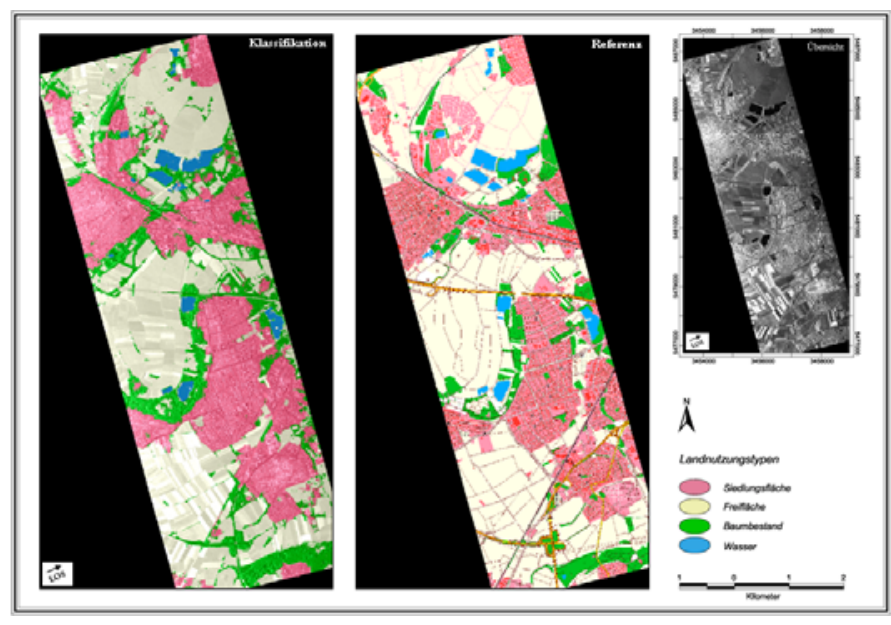

Figure 1. Left: classification result (red: buildt-up, green: forest, blue: water, bright: agriculture); Center: reference data; Right: input data = EEC image.

\section{A. Geocoding Terrain Corrected - First Results}

To demonstrate a first version of this GTC processor we performed a SAR to DEM registration for the test site of Mannheim. The used high resolution DEM was acquired with an airborne laser-scanner. It has a resolution of $1 \mathrm{~m}$.

The most obvious problem we had to deal with was a positioning error between the laser-scanning DEM and the SAR image. Such positioning errors are very frequent due to preliminary orbits or orbit errors.

"Fig. 2b" illustrates a geocoded image without correct registration to the DEM shown in "Fig. 2a". The offset evokes many artefacts in urban terrain, because the edges of the buildings in the SAR image are not projected correctly onto the edges of the underlying DEM. Such offsets are difficult to detect in geocoded images.

To estimate the offset between the SAR image and the DEM tie-points have to be measured. However, the measurement of tie-points directly from a DEM is less appropriate since the appearance of an elevation model is very different to a SAR image. Therefore, we determined these differences in slant range geometry. To get a comparable SAR image we calculated a simulated incidence angle map (IAM) from the reference laser-scanning DEM based on the SAR sensor geometry. Then, we projected it into slant range geometry. The simulated IAM now shows a good agreement with real SAR data with respect to the geometric properties ("Fig. 3"). A change of incidence angle corresponds more likely to a change of SAR backscatter. In particular buildings appear in the simulated IAM with the typical shadow and layover regions. The resulting IAM-SAR differences of the test site Mannheim were of approximately 13 pixel in each direction, which corresponds to $9 \mathrm{~m}$ in range and azimuth.

From this, it follows that a fine registration of the SAR image to the DEM respectively the simulated IAM is essential. This is done within the GTC processor by the help of ground control points (GCPs). In our case study GCPs are measured manually between the slant range SAR image (pixel co- 
ordinates) and a geocoded simulated IAM (map co-ordinates). The received GCPs are used to adjust the radar geometry (Range and Doppler equations) by a least squares adjustment. The resulting GTC is presented in "Fig. 2c" and "Fig. 4".

\section{B. Discussion of GTC Results}

In the GTC a shift of the buildings and elevated objects towards the sensor can be observed. This phenomenon comes from the layover effect. The layover caused from the ground, the wall, and the roof is smeared in the geocoded image ("Fig. $2 \mathrm{c}$ ") from before the building towards somewhere on the roof. Especially in far range and if a building is relatively high and narrow the layover is interrupted by a layover zone with solely backscatter from the ground and the wall. These reflections are much lower without the high contribution of the roof, which is especially high if a total reflection occurs (when the plane normal points to the sensor).

\section{CONCLUSION}

The TerraSAR-X orthorectification service with the two basic geocoded products was presented. In comparison to the GEC image the EEC can provide higher pixel location accuracy, because small scale features (like hills or river valleys) can be correctly ortho-rectified. The global operationally available DEM-database was outlined.

Further, a first version of an experimental Geocoded Terrain Corrected (GTC) processor was presented. Deviations between the input SAR image and a high resolution laserscanning DEM were detected and corrected. The GTC is derived by a least squares adjustment of the radar geometry with the aid of tie-points. Further work will concentrate on automatic tie-pointing and an improved simulation of a SAR image from a DEM.

\section{REFERENCES}

[1] G. Schreier, "Geometrical Properties of SAR Images", in: SAR Geocoding and Systems, G. Schreier (Ed.), Wichmann, Karlsruhe, 1993, pp. 103-134.

[2] A. Roth, M. Huber, D. Kosmann, "Geocoding of TerraSAR-X Data", in: In: Proc. of 20 'th International Congress of the ISPRS, Istanbul, Turkey, Commission III, 2004, pp. 840-844.

[3] A. Roth, W. Knöpfle, G. Strunz, M. Lehner, P. Reinartz, "Towards a Global Elevation Product: Combination of Multi-Source Digital Elevation Models", in: Proc. of Joint International Symposium on Geospatial Theory, Processing and Applications, Ottawa, Canada, 2002.

[4] W. Knöpfle, S. Dech, "Visualistion of Interferometric Products Derived rom ERS1/2 Tandem Pair Data", in: Proc. of IGARSS'99, Hamburg, Germany, Vol. II, 1999, pp. 1378-1380.

[5] DLR's TerraSAR-X project website: "Level 1b Product Format Specification" http://www.caf.dlr.de/tsx/documentation/TX-GS-DD-3307.pdf

[6] T. Esch, "(Extraction of information on urban structures from high resolution SAR data) Extraktion siedlungsstruktureller Informationen aus höchst auflösenden Radardaten”, Dissertationsschriftenreihe der, Bayerischen Julius Maximilians Universität Würzburg, 2006.

[7] U. Soergel, K. Schulz, U. Thoennessen, U. Stilla, "Utilization of 2D and 3D information for SAR image analysis in dense urban areas", in: Proc. of 4th European conference on synthetic aperture radar, EUSAR 2002, Berlin: VDE, pp. 429-434.

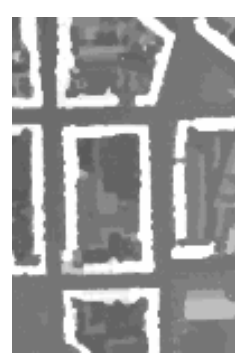

a)

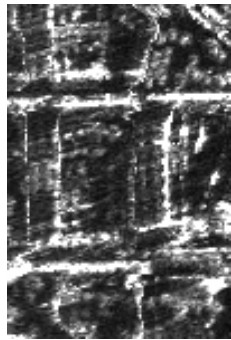

b)

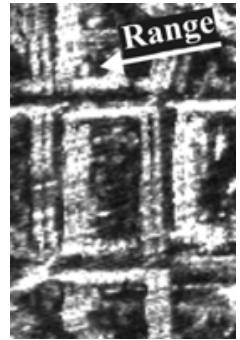

c)
Figure 2. Building footprint in a) Laser-scanning DEM, b) GTC without adjustment, c) GTC with adjustment

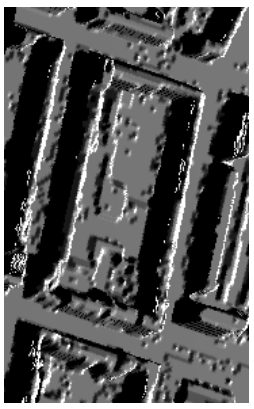

a)

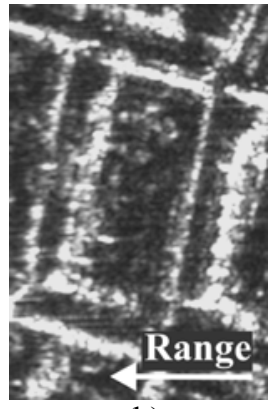

b)
Figure 3. a) Simulated Incidence Angle Map (IAM) in slant range (dark: shadow, grey: specific incidence angle, white: layover areas); b) slant range SAR input image

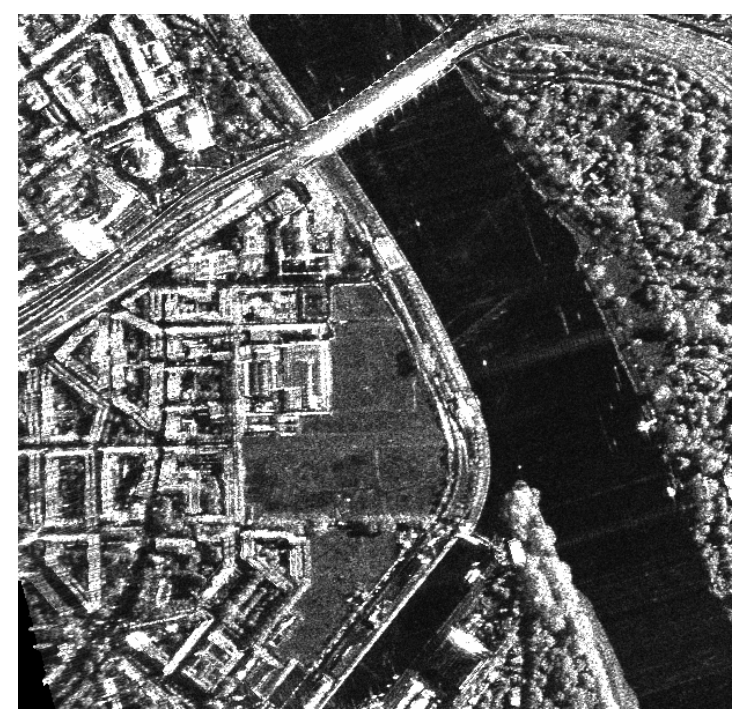

Figure 4. GTC with adjustment to laser-scanning DEM 